\title{
LA PAREJA EN DISPUTA. EN TIEMPOS DEL SEXO SIN EROTISMO. ¿POR QUÉ NOS CUESTA TANTO ESTAR JUNTOS?
}

DE LUCIANO LUTEREAU

\author{
Sandra Borges Conde \\ Especialista en Psicoterapia Psicoanalítica del IUPA \\ Montevideo, Uruguay \\ Correo electrónico: sborges15@hotmail.com \\ ORCID: 0000-0002-5544-7470
}




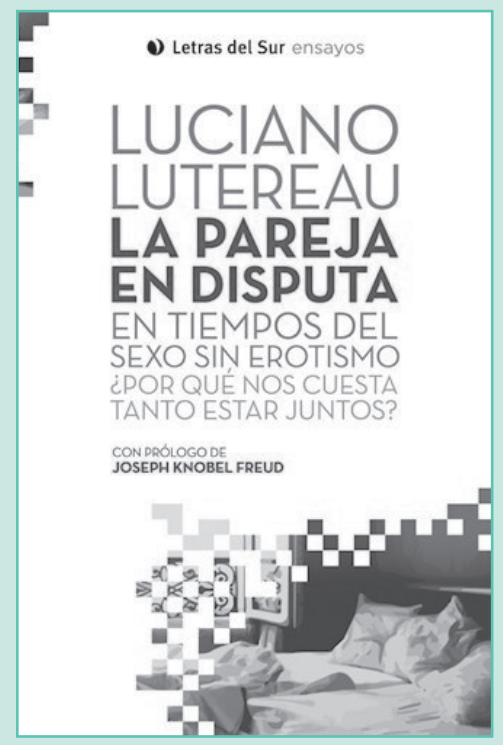

Título: La pareja en disputa. En tiempos del sexo sin erotismo. ¿Por qué nos cuesta tanto estar juntos?

Autor: Luciano Lutereau

Año: 2020

Editorial: Letras del Sur

Ciudad: Buenos Aires

Páginas: 206 
Hace más de un año, nadie sabía lo que se avecinaba. La pandemia que había comenzado en China se esparcía por Europa y, sin embargo, persistía la esperanza de que no llegara a nuestras tierras. Luego sobrevino la cuarentena, el miedo, la incertidumbre, las vacunas, la virtualidad y, con ello, la modificación de hábitos y rutinas. Se tejieron todo tipo de proyecciones sobre las opciones que se abrían en el ámbito personal, psicológico y hasta filosófico, como si este fenómeno que estamos transitando fuera una oportunidad única para repensar nuestra manera de vivir la vida.

Luciano Lutereau, psicoanalista, doctor en Filosofía y doctor en Psicología de la Universidad de Buenos Aires (UBA), es autor de varios libros, donde analiza el impacto de los cambios sociales y culturales a nivel personal y familiar. Entre estos se encuentran Por qué los hombres odian a las mujeres (2017), Más crianza, menos terapia. Ser padres en el siglo XXI (2018), Matar al macho. Varones deconstruidos, feministas y otras misoginias (2019) y El fin de la masculinidad. Cómo amar en el siglo XXI (2020).

En La pareja en disputa. En tiempos del sexo sin erotismo. ¿Por qué nos cuesta tanto estar juntos? (2020), Lutereau realiza un giro en su abordaje teórico: ya no se centra en los hombres y en las mujeres de manera separada, sino que pone en discusión la problemática de las dinámicas vinculares dentro de la pareja en el marco de la hipermodernidad.

El autor plantea la hipótesis de que, desde hace años, se ha entrado en una fase de disolución del erotismo como lazo entre las personas. La pandemia parece haber puesto de manifiesto una realidad vincular; algunos movimientos estaban en marcha desde antes y, con la pandemia, se pueden visibilizar mejor. 
Tinder, Happn y otras redes sociales de citas llegaron al mundo para instalarse y funcionan a modo de «delivery sexual amoroso». Las redes sociales son hoy el artilugio detrás del cual nos escondemos para llevar a cabo la conquista sin tener que exponernos, para poder luego pasar a otra cosa rápidamente. Pareciera que hombres y mujeres no quieren saber de nada con relaciones estables, ni de familia ni de algo que pueda parecerse a un compromiso. Lutereau afirma que el $70 \%$ de las parejas se separa luego de su primer hijo.

Nos encontramos en un tiempo de sexo sin erotismo, dice el autor, de encuentros exprés sin ternura. Las parejas se arman desde una misma identidad, no desde la diferencia.

El amor romántico del siglo XVIII y XIX es historia. Las redes sociales y las nuevas tecnologías modificaron las formas de comunicarse y... ¿de amar? Las personas se conocen a través de una pantalla y establecen vínculos desde allí: vínculos efímeros, líquidos, superfluos.

¿Son estos los nuevos vínculos que plantea la posmodernidad? El amor a la carta es parte de una sociedad de consumo que todo lo quiere ya. Todo está marcado por la satisfacción de necesidades instantáneas y efímeras. Las relaciones comienzan y se evaporan en el mismo instante, en lo que la apuesta no trasciende el presente y los vínculos no apuntan a la perdurabilidad. ¿Estaremos destinándonos a encontrar a nuestras parejas en un sistema operativo? El obsesivo intenta controlar la pasión, pero sucumbe a la pasión del control. El histérico busca poner distancia.

En el siglo xxI, la pareja queda separada del amor, reducida a algo que se tiene o no; tener pareja pareciera ser más importante que amar. El temor a la soledad es lo que subyace a todo esto y es lo que se buscaría contrarrestar al tener una pareja. A propósito, Knobel Freud se pregunta en el prólogo: ¿no será que no sabemos estar juntos porque no hemos aprendido a estar solos? 
La nuestra es una época de exacerbación de la autosuficiencia y el desarrollo personal como indicadores del éxito. Nos encontramos asistiendo a un momento histórico caracterizado por un paso del tiempo acelerado y avances tecnológicos vertiginosos que imponen cambios en las subjetividades y en las relaciones intersubjetivas.

Es un tiempo caracterizado por la incompletud, la vulnerabilidad, la falta de certezas y la inmediatez, en el que el cumplimiento de los deseos alcanza, quizá, su mayor representación en los vínculos descartables.

Estos vínculos tienen un carácter temporal, se pueden romper en cualquier momento y de manera unilateral. Esto va de la mano del compromiso: cuanto menor es, menos daño se puede generar. Los vínculos son tratados de la misma manera que los objetos de consumo.

La ternura, afirma el autor, es algo que parece haberse desplazado del vínculo de pareja a otros vínculos. Mantener relaciones sexuales tiene más que ver con la performance que con el alcance erótico. Algo de la función de cuidado y de intimidad que conlleva el erotismo no se juega en el vínculo amoroso y está desplazado al grupo de pares. ¿Qué queda de la relación de pareja cuando no se puede hacer del otro alguien con quien vivir la dependencia del cuidado?. No poder jugar la dependencia con el otro tiene como efecto un temor enorme a depender.

Asimismo, el acto sexual está sobrevalorado, se vuelve modelo del encuentro con el otro a costa del erotismo. Lutereau ve en las aplicaciones «del amor» dispositivos de seducción que no posibilitan el lazo, pues muchas de las veces ni siquiera se concreta el encuentro. ¿Dónde queda la mirada, el chiste, la conversación?

En este sentido, para entender esto último, podría ser útil revisitar el concepto de intimidad, en el que Lutereau no profundiza demasiado. La privacidad es con uno mismo, mientras que la intimidad no es posible sin otros. La intimidad supone un compartir con, así como el plural nosotros. 
El encuentro es con otro, con quien se comparten vivencias, donde dos sujetos se conectan y comparten estados subjetivos sin perder la vivencia de ser sujetos separados y, a la vez, estar en un espacio de comunión. De esta manera, se entiende la intimidad como una experiencia vincular en la que lo compartido crea un espacio común que puede estrecharse tanto como expandirse en virtud de sus intercambios. Así, la intimidad se experimentaría como una expansión del yo hacia el nosotros.

En el mundo que hoy habitamos, las categorías para entender las relaciones afectivas se revisan constantemente y nos plantean el desafío de elegir un proyecto que no excluya la libertad y la realización personal, de vincularnos más allá de las formas rígidas de otro tiempo y de repensar conceptos como soltería, fidelidad, compromiso y erotismo.

Escribir mientras un proceso histórico sucede no es sencillo y se convierte en un desafío. El planteo realizado por Lutereau es novedoso, pertinente y va en consonancia con lo que pensadores como Bauman, Lipovetsky y Badiou han planteado en relación al tema de la hipermodernidad.

Igualmente, en algunos pasajes del libro, se cae en afirmaciones y generalizaciones un tanto lineales, que pueden llevar a cierto reduccionismo en la manera de concebir determinados funcionamientos psíquicos. Seguir pensando en la noción unidimensional del individuo como sujeto del inconciente, cerrado y determinado a partir del tránsito por lo edípico, desconoce el peso instituyente que tiene la vincularidad presente en el devenir del sujeto.

De todas formas, lo planteado en La pareja en disputa..., publicado por Letras del Sur, ayuda a seguir pensando y arriesgando hipótesis sobre los desencuentros entre hombres y mujeres, tan comunes en el mundo contemporáneo. 